\title{
Study on the Therapeutic Efficacy of a Polyphitho Therapeutic Compound in Primary and Secondary Lymphedema
}

\author{
Sandro Michelini, MD, ${ }^{1}$ Vincenzo Gasbarro, MD, ${ }^{2}$ Marcello Izzo, MD, ${ }^{2}$ and Francesco G. Albergati, MD ${ }^{3}$
}

\begin{abstract}
The role of the interstitial matrix in regulating exchanges and interactions at the level of the microvascular units, between the corpuscular component and the vascular and nerve structures, has long been known. Equally known are the objective and subjective clinical manifestations that these pathologies trigger in the patient, both in primary and secondary forms: embarrassment, asthenia, alterations of exteroceptive and proprioceptive sensitivity, pain, reduced capacity, and functional autonomy, affecting both the lower and the upper limbs. The authors studied 136 patients with I and II clinical stage lymphedema according to the International Society of Lymphology stadiation. Patients were treated with Lymdiaral, 20 drops three times a day for 90 consecutive days. The following parameters were examined in basal conditions and after treatment: ultrasound measurement of suprafascial thickness, short form healthy survey version 12 (SF12), body mass index, and limb circumferences in specific points of reference. The results demonstrate the effectiveness of the therapeutic principle both in the reduction of limb circumferences and in the improvement of the parameters related to the quality of life expressed by the SF12 items. There were no substantial differences in the results between primary and secondary forms.
\end{abstract}

Keywords: lymphedema, medical, therapy

\section{Introduction}

$\mathbf{P}$ RIMARY AND SECONDARY LYMPHEDEMA THERAPY improves the patient's quality of life in the long term, given the chronic nature of the pathology. ${ }^{1-4}$ The various therapeutic proposals, often administered as associations, demonstrate the limits that are observed in clinical practice with respect to these pathological conditions. Surgical treatment, in its various techniques proposed, still shows a high percentage of therapeutic failures (substantially a postoperative immobility) and still today it is not possible to identify patients who are candidates to experience a certain clinical improvement after surgery. ${ }^{5}$ Physical therapy requires periodic interventions and continuous clinical monitoring that can demonstrate the maintenance of the results obtained thanks to the therapy for shorter or longer periods, this aspect being strongly conditioned by the wearing of an elastic garment for long periods. 6,7 Drug therapy uses the two categories of benzopyrones ${ }^{8,9}$ : alpha-benzopyrones $^{10}$ (to which coumarins belong) and gamma-benzopyrones (to which bioflavonoids belong). ${ }^{11}$ The therapeutic effect, ${ }^{12,13}$ not constant, dose dependent and strongly conditioned by the individual response of single patients is highlighted essentially in the I and II clinical stage, when fibrosis has not yet entirely conglobated also the wall of the initial lymphatic vessels and lymphatic collectors that, under these conditions, no longer respond to pharmacological stimuli. ${ }^{14-20}$ This study stems from the need to ascertain the effect of Lymdiaral in the cases of primary and secondary stage I and II lymphedema, also considering the multiple effects of the compound both with respect to chronic inflammation (involving the tissues in these clinical forms, which also structurally disrupt the interstitial matrix, a fundamental biological network between cells and vessels and nerves) and toward the resorption of interstitial fluids, the reduced capillary permeability, and the overall draining action. ${ }^{21,22}$ The Matrix itself, for too long considered only an "inert tank," is today

\footnotetext{
${ }^{1}$ Department of Vascular Rehabilitation, San Giovanni Battista Hospital, Rome, Italy.

${ }^{2}$ Department of Vascular Surgery, Ferrara University, Ferrara, Italy.

${ }^{3}$ Center of Microcirculation and Microangiology-High Speciality Care and Research Medical Institute, Monza Policlinic, Monza, Italy.
}

(C) Sandro Michelini et al., 2020; Published by Mary Ann Liebert, Inc. This Open Access article is distributed under the terms of the Creative Commons License (http://creativecommons.org/licenses/by/4.0), which permits unrestricted use, distribution, and reproduction in any medium, provided the original work is properly cited. 


\section{Average reduction of supra-fascial thicknesses at the end treatment}

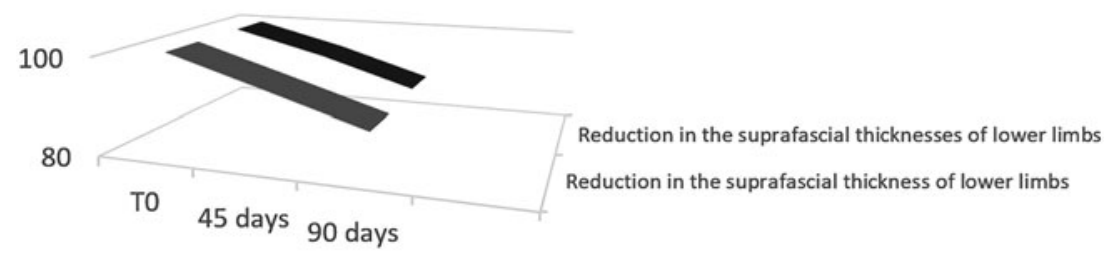

- Reduction in the suprafascial thickness of lower limbs

FIG. 1. Average reduction of suprafascial thicknesses at the end treatment.

seen as a fundamental component in the biological processes of cellular and tissue exchange and remodeling; as a matter of fact, all the fundamental disease categories are born and developed at a matrix level: acute and chronic inflammations, chronic degenerative diseases, dysplasia, and even neoplasms. A fundamental role of physiological and functional balance must be safeguarded, mainly from the oxidative processes that determine aging and loss of function. Hence the need, in a chronic pathology such as lymphedema, ${ }^{23-28}$ to resort to active principles capable of keeping the equilibrium of the Matrix alive and vital in its work of continuous and dynamic biofunctional remodeling. ${ }^{29}$

\section{Materials and Methods}

One hundred thirty-six patients (120 women with a mean age of 54.6 years and 16 men with a mean age of 59.1 years) with primary lymphedema were studied $(69,63$ women and 6 men) and secondary lymphedema (67, 56 women and 11 men). One hundred ten (97 women and 13 men) involved the lower limbs and 26 (23 women and 3 men) the upper limbs. Eighty-four ( 79 women and 5 men) presented a I clinical stage; 52 (41 women and 11 men) a II clinical stage. The following inclusion criteria, more selective than in previous literature, were identified in the study:

- Age between 18 and 70 years (average age 56.4 years)

- Presence of primary or secondary lymphedema

- I or II clinical stage according to the Consensus Document of the International Society of Lymphology. ${ }^{10}$

The following exclusion criteria have also been identified:

- Pregnancy

- Chronic renal failure
- Heart failure

- Chronic liver disease

- Allergic diathesis

- Use of drugs with vasodilating action

- Use of diuretics.

The average height of the subjects examined was $165 \mathrm{~cm}$ in women and $170 \mathrm{~cm}$ in men; the average weight 66.9 and $77.6 \mathrm{~kg}$, respectively. The average body mass index (BMI) was 24.8 in women and 26.7 in men.

All patients underwent a 15-day washout from any specific vasoactive therapies taken for a long time.

All the patients were given 20 drops three times a day for 90 consecutive days of a compound thus constituted (and, reported on the side, there are the daily dosages of each component distributed in the three administrations):

Taraxacum $\varnothing \mathrm{g} 0.117 /$ day-it has a purifying effect by stimulating liver and kidney functions.

Calendula $\varnothing \mathrm{g} \mathrm{0.066/day-contains} \mathrm{carotenoids} \mathrm{that} \mathrm{en-}$ rich the tissue with water and flavonoids that have an antibacterial and anti-inflammatory action.

Arsenicum album D8 g 0.015/day-it has antiinflammatory and pain-relieving properties.

Chelidonium D8g 0.007/day-contains alkaloids, carotenes, and proteolytic enzymes with reparative and antiinflammatory properties.

Leptandra $\varnothing \mathrm{g} \mathrm{0.004/day-with} \mathrm{antiphlogistic} \mathrm{effect.}$

Echinacea D3 g 0.004/day-contains polysaccharides with an immunostimulant effect and flavonoids with an antibacterial and anti-inflammatory action.

Phytolacca D2 g 0.003/day-contains saponins that have an anti-inflammatory and pain-relieving action and phytolaccatoxins with anticancer effects. a

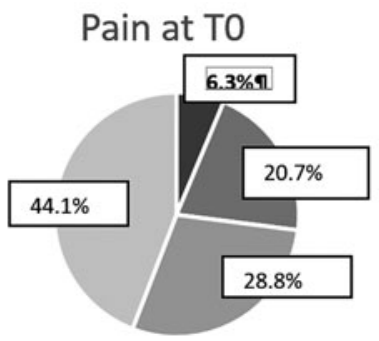

- Much = A little $=$ Verylittle $=$ Not at all

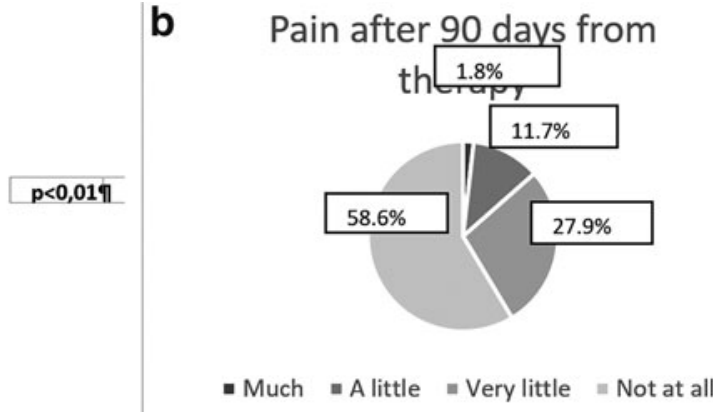

- Much = A little = Very little $=$ Not at all

FIG. 2. (a) Pain at T0. (b) Pain after 90 days from therapy. 
a

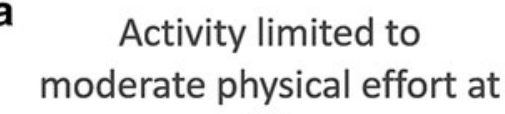

TO

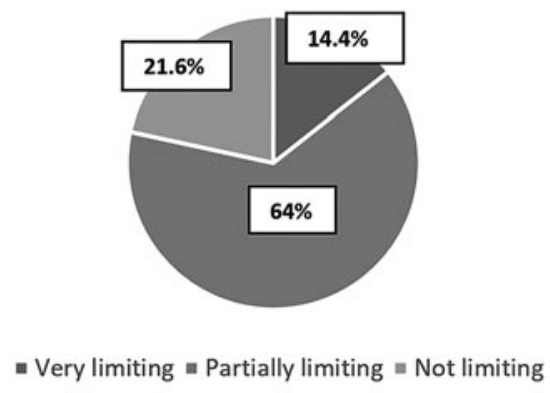

b

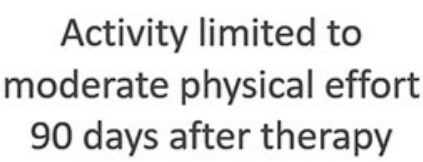

$\mathrm{p}<0,01$ ๆ

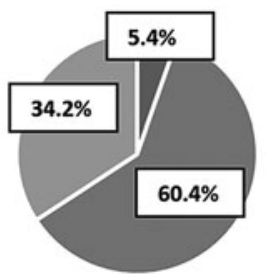

- Very limiting = Partially limiting

N Not limiting

FIG. 3. (a) Activity limited to moderate physical effort at T0. (b) Activity limited to moderate physical effort 90 days after therapy.

Carduus marianus D1 g 0.003/day-contains, in particular, Silymarin that has an antioxidant and hepatoprotective action, which makes it indicated in various forms of hepatocellular suffering (it accelerates the liver regeneration process by increasing the metabolic activity of liver cells; it stimulates protein synthesis; defense function against several hepatotoxic substances, including alcohol).

Condurango D2 g 0.0015/day-contains flavonoids with antiphlogistic effect on tissue.

Hydrastis $\varnothing \mathrm{g} \mathrm{0.0015/day-its} \mathrm{vasoconstrictor} \mathrm{effect,} \mathrm{es-}$ pecially in the venous side, reduces capillary permeability and ultrafiltration.

Lycopodium D2 g 0.0015/day-stimulates the metabolism and the activity of the excretory apparatus.
Sanguinaria D8 g 0.0015/day-has diuretic, spasmolytic, and anti-inflammatory effects.

The following parameters were examined before starting the treatment (T0) and at the end of treatment (T1):

- Measurement of suprafascial thickness in the affected limb performed with high-resolution ultrasonographer with linear probe.

- Submission of the short form healthy survey version 12 (SF12) quality-of-life questionnaire.

- BMI.

- Measurement of circumferences in certain points of reference, clearly distinguished for the upper limb and the lower limb (as per diagram a and b).

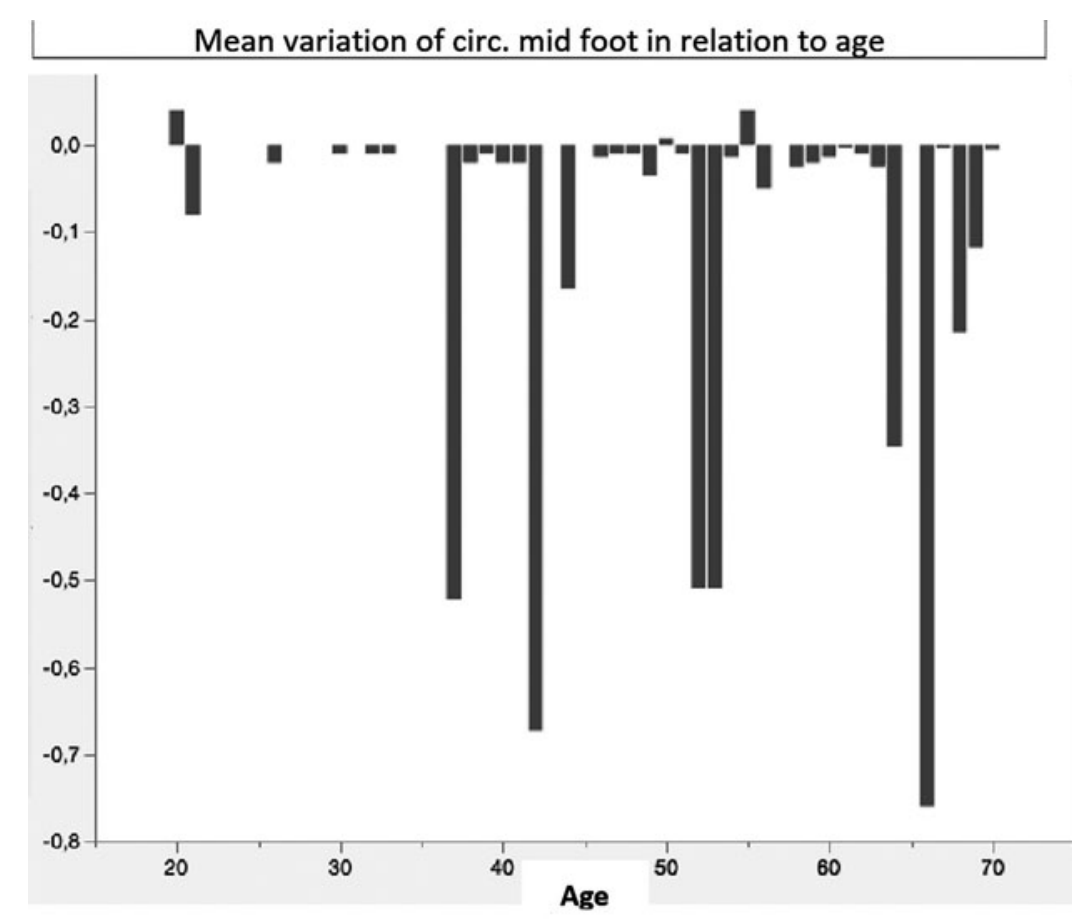

FIG. 4. Mean variation of circumferences midfoot in relation to age. 


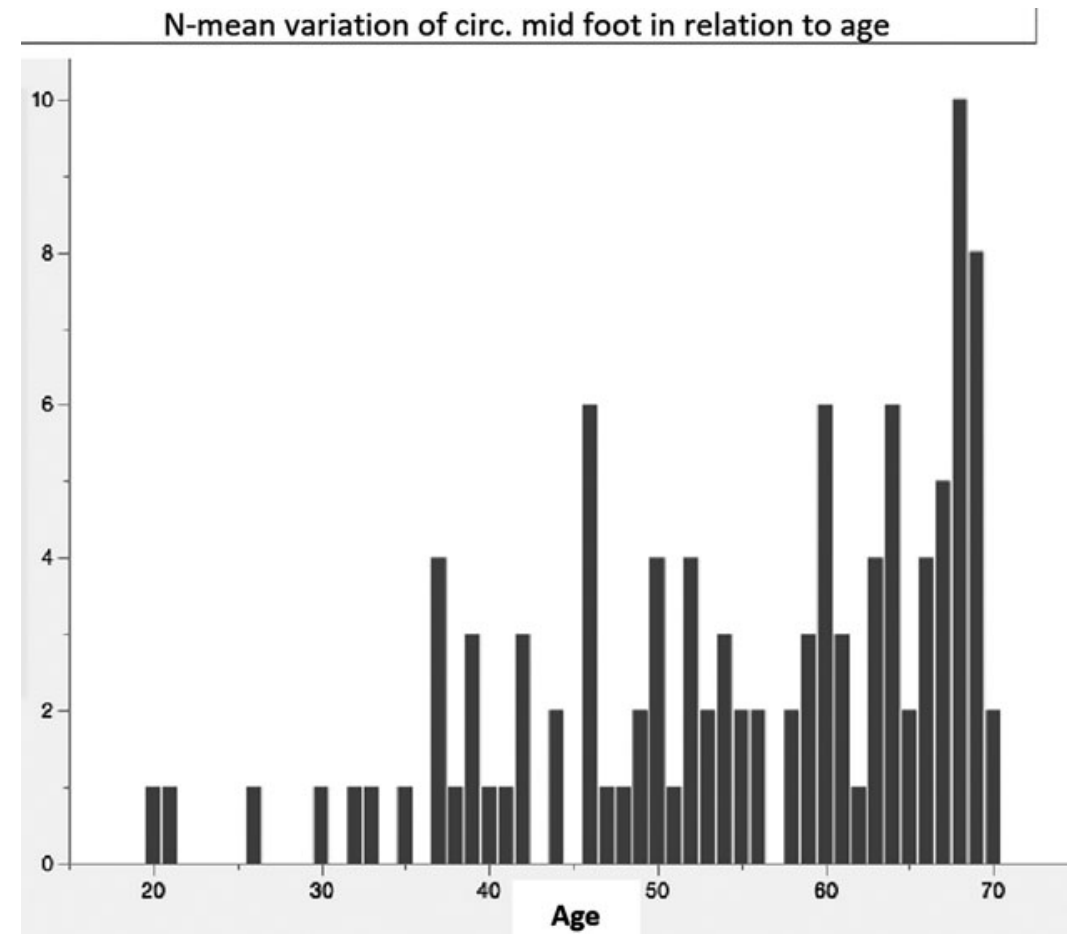

FIG. 5. N-variation of circumferences midfoot in relation to age.

In particular, the circumferences in basal conditions and after 90 days of treatment were detected at the following points of reference:

$\checkmark$ Lower limb: Midfoot, $10 \mathrm{~cm}$ above the internal malleolus, $20 \mathrm{~cm}$ above the inner malleolus, $30 \mathrm{~cm}$ above the inner malleolus, $40 \mathrm{~cm}$ above the inner malleolus, $50 \mathrm{~cm}$ above the inner malleolus, $60 \mathrm{~cm}$ above the inner malleolus, and $70 \mathrm{~cm}$ above the internal malleolus.

$\checkmark$ Upper limb: first interdigital space, $10 \mathrm{~cm}$ above the wrist, $20 \mathrm{~cm}$ above the wrist, $30 \mathrm{~cm}$ above the wrist, $40 \mathrm{~cm}$ above the wrist, $50 \mathrm{~cm}$ above the wrist, $60 \mathrm{~cm}$ above the wrist, and $70 \mathrm{~cm}$ above the wrist.

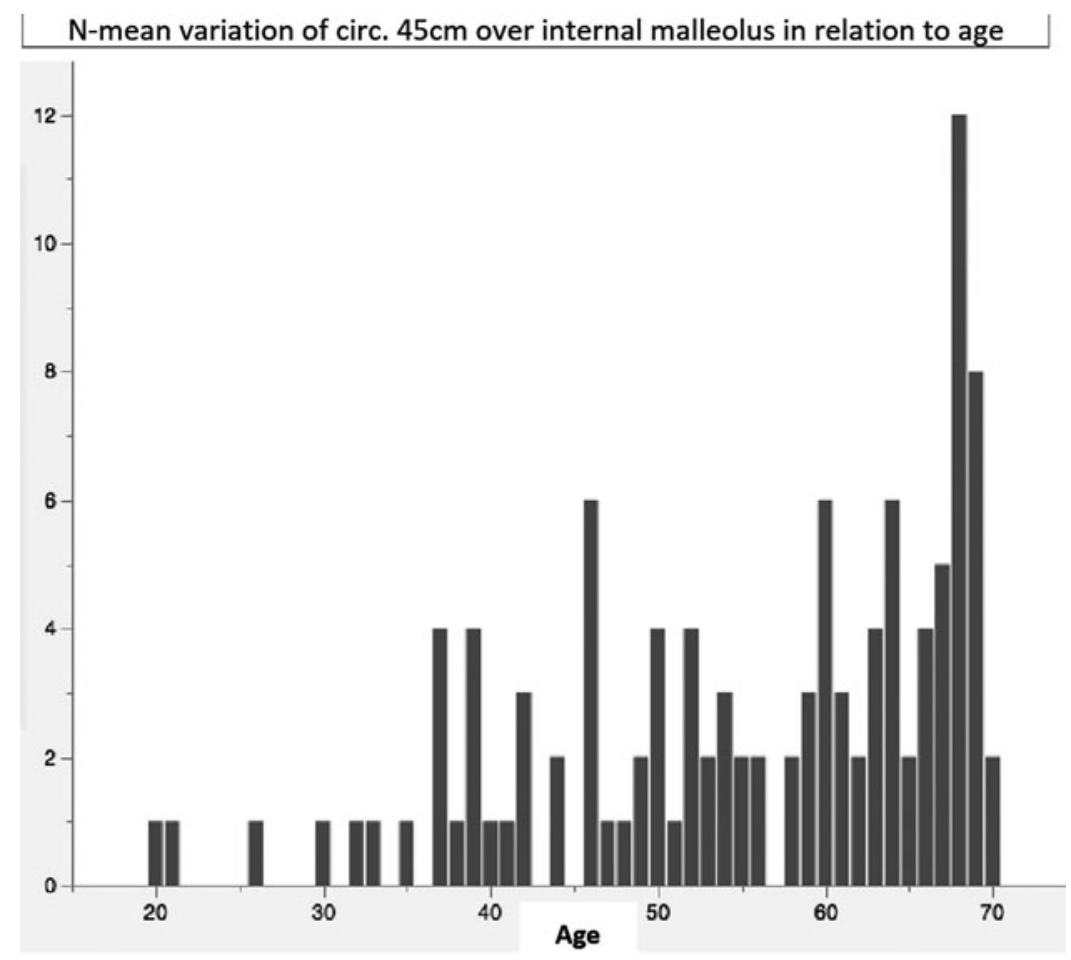

FIG. 6. N-mean variation of circumferences $45 \mathrm{~cm}$ over internal malleolus in relation to age. 

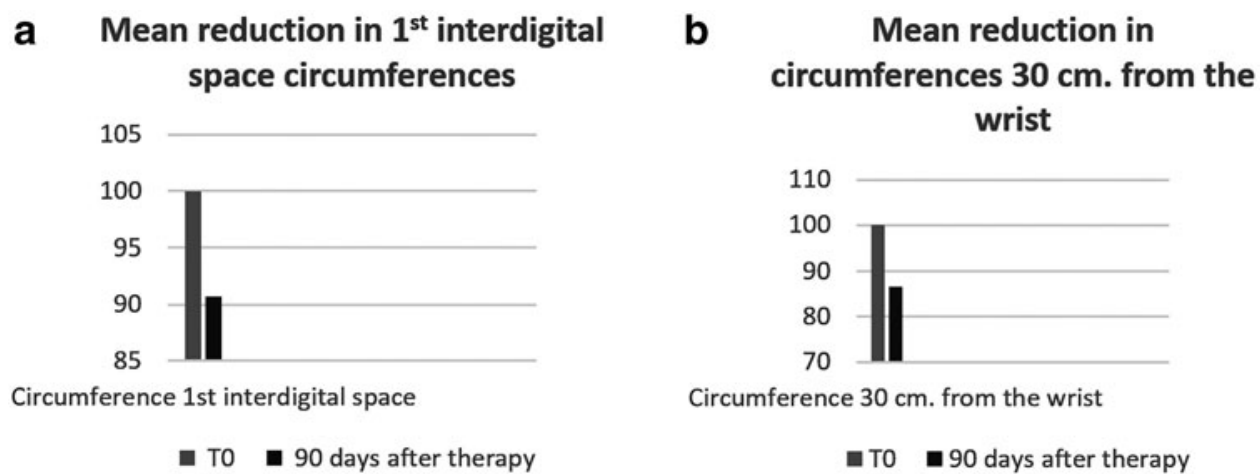

FIG. 7. (a) Mean reduction in first interdigital space circumferences. (b) Mean reduction in circumferences $30 \mathrm{~cm}$. from the wrist.

\section{Results}

At the end of the 90 days of treatment the checks of the various parameters taken into consideration have demonstrated the following results:

- High-resolution ultrasound probe measurements of the suprafascial thicknesses of the affected limbs have shown an average decrease in the measurements compared with the basal values of $11.5 \%$ (12.1 for the upper limb, 11.1 for the lower limb) $\pm 8.1 \%$ (Fig. 1).

- In relation to the SF12 quality-of-life questionnaire it was noted in particular that:

- With reference to pain as an obstacle to work performance, the percentage of "in no way" responses after treatment has risen to $58.6 \%$ compared with $44.1 \%$ of responses before the start of treatment with a simultaneous decrease in "much" from $6.3 \%$ to $1.8 \%$ (Fig. 2a, b).

- The same limitation in activities that require a moderate physical effort showed a decrease in the response "very limiting" from $14.4 \%$ in basal conditions compared with $5.4 \%$ after treatment with a simultaneous increase in the response "not limiting" that in basal conditions was $21.6 \%$ and became $34.2 \%$ after treatment (Fig. 3a, b).

- In relation to the overall health status (cenesthesia) at the end of treatment, there was a $15.4 \%$ increase in the response "excellent" compared with the basal conditions with a simultaneous decrease in "poor" from $16.8 \%$ to $4.9 \%$.

- The BMI did not undergo substantial changes both in the primary and secondary forms of lymphedema (regardless

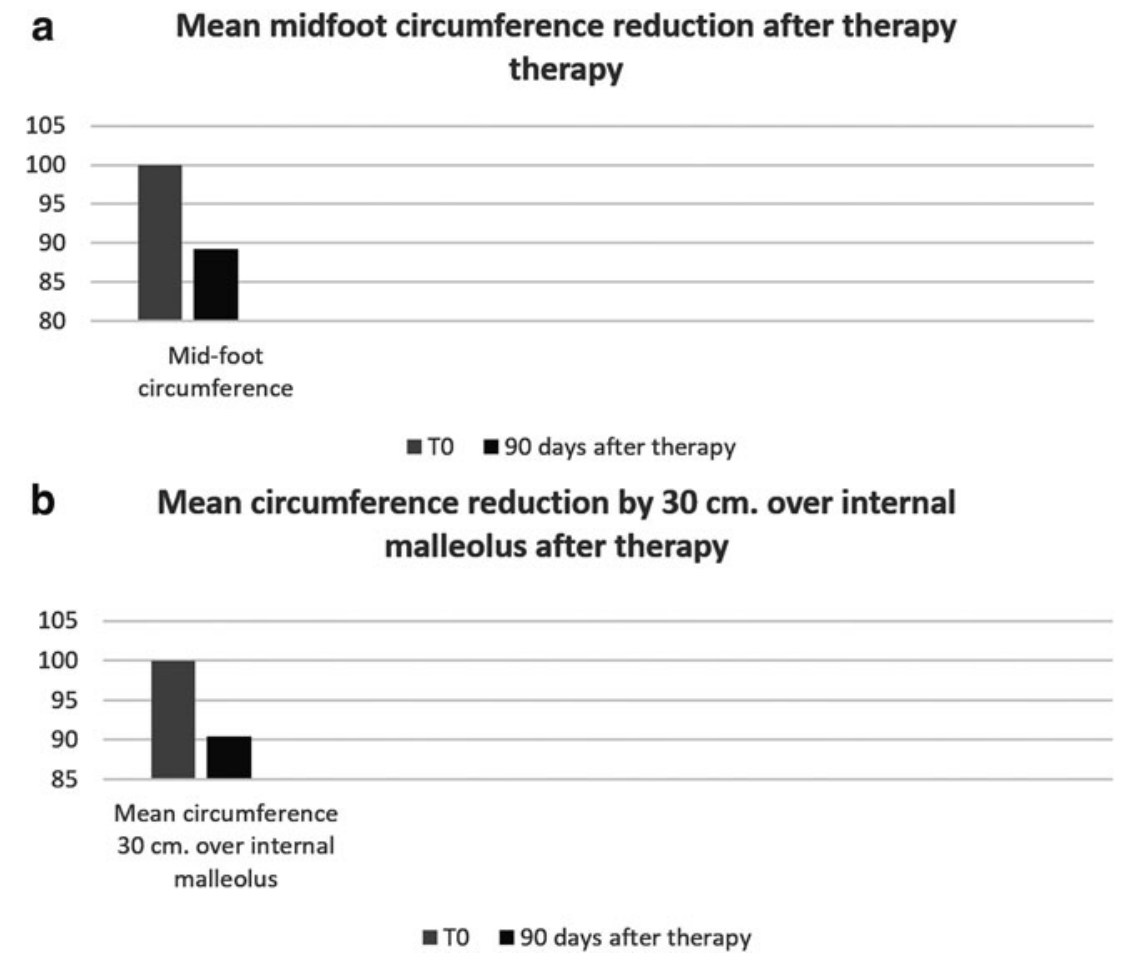

FIG. 8. (a) Mean midfoot circumference reduction after therapy. (b) Mean circumference by $30 \mathrm{~cm}$. over internal malleolus after therapy. 
of the location in the lower or upper limbs). The average decrease of $0.9 \%$ in the value, found at the end of treatment, judged "not significant" was also linked to the greater physical activity performed on average by the subjects and to the respect of improved dietary regimes. Furthermore, the change in BMI was not influential in the modifications of the lower limbs, whereas it showed a greater influence in the circumference decreases related to the locations in the upper limb.

- In relation to the final circumferences found at the various levels established in the study, an average decrease of $9.8 \%$ was found with greater evidence in women compared with men and in the youngsters compared with elderly (both for the forms affecting the lower and upper limbs) (Figs. 4-6).

In particular it was highlighted:

1. In the upper limb the circumferences at the level of the first interdigital spaces showed an average decrease of 9.3\% compared with the basal measurements, whereas at $30 \mathrm{~cm}$ from the wrist there was an average decrease of $13.5 \%$ (Fig. $7 \mathrm{a}, \mathrm{b}, p<0.005$ ).

2 . In the lower limb the circumferences detected in correspondence with the midfoot showed, after treatment, an average decrease of $10.8 \%$ compared with basal findings, whereas the average circumferences detected at $30 \mathrm{~cm}$ above the internal malleolus showed an average decrease of $9.6 \%$ (Fig. 8a, b, $p<0.01$ ).

\section{Discussion and Conclusions}

The results on the efficacy of the product are rather encouraging in the control of inflammatory, postsurgical, and primitive enema. The beneficial actions were also useful in the management of pain and symptoms related to edema, making patients more adherent to the medical, physical, and surgical therapies they must or will undergo. The increase in relational abilities, in the long and troubled therapeutic course of lymphedema characterized by exacerbations, recurrences, and sometimes therapeutic failures, allows better clinical results and a significant increase in quality of life.

To date, the natural active ingredients do not replace (nor are they intended to do so) the physical or surgical therapies improved over the years, which at least reduce the worsening of chronic lymphedematous pathology; if anything, the association of these substances to physical therapy, which may precede or follow any surgical treatment, shows the best results with regard to the containment of edema and the related symptoms.

Furthermore, the presence on the market of formulations, which in a single mixture offers a synergistic therapeutic action against phlogosis, pain, tissue oxidation, and the aging of the interstitial matrix (due to the increasing fibrosis) makes pharmacological therapy affordable on the term by almost all patients.

The observations showed stability in the results and the patients continued with the therapy. It was not necessary to carry out a water balance because the indirect diuretic effect also includes protein reabsorption.

The action mechanisms of the single constituents of the compound determine an exclusive overall effect on the interstitial matrix improving its function of biological network, both for the overall anti-inflammatory and draining result.
In the literature, and the clinical results obtained in this study together with the improvement of the quality of life achieved (with the possibility of reducing costs for patients) and the excellent biological tolerability, allow us to advise and extend the combined use of the product with physical therapy to all patients suffering from lymphedema, regardless of its genesis, to obtain the best clinical result, without obviously getting complete recovery from the disease, as no treatment currently available can do. Regarding biological tolerability, the control tests did not show any type of negative side effect on liver and kidney function, nor on myelopoiesis.

The study was appropriately conducted on patients presenting I and II clinical stage lymphedema as in stage III tissue fibrosis that is established at a local level prevents the same substances from acting, above all with the antiinflammatory effect, given that, in those anatomical conditions, the entire structure of the lymphatic collector is anatomically involved in the fibrosclerotic process developed in chronic progressive forms. This preliminary study demonstrates incontrovertible clinical effects that, however, must be investigated with more numerous and more varied case studies from the point of view of the representativeness of the two genders and of the clinical localizations.

\section{Disclaimer}

This study has been carried out in accordance with the Helsinki Declaration (1975 and 2008), especially given that the association of the mixture of active substances indicated in the article has already been on the market in Europe, from several years and is regularly prescribed by many doctors. It was our intention to verify the clinical effects (with the indicated dosages) actually obtained in a fairly good range of affected populations. All treated patients signed an informed medical consent and their data were treated with respect for privacy.

\section{Author Disclosure Statement}

No competing financial interests exist.

\section{Funding Information}

No funding was received for this study.

\section{References}

1. Lee B, Andrade M, Bergan J, Boccardo F, Campisi C, Damstra R, Flour M, Gloviczki P, Laredo J, Piller N, Michelini S, Mortimer P, Villavicencio JL. Diagnosis and treatment of primary lymphedema. Consensus Document of the International Union of Phlebology (IUP)-2009. Int Angiol 2010; 29:454-470.

2. International Society of Lymphology. The diagnosis and treatment of peripheral lymphedema: 2013 Consensus Document of the International Society of Lymphology. Lymphology 2013; 46:1-11.

3. Gasbarro V, Michelini S, Antignani PL, Tsolaki E, Ricci M, Allegra C. The CEAP-L classification for lymphedemas of the limb: The Italian experience. Int Angiol 2009; 28:315-324.

4. Moffatt C, Partsch H, Schuren J, et al. Compression Therapy: A position document on compression bandaging. Frederiksberg C, Denmark: International Lymphoedema Framework; 2012.

5. MacKay D, Miller AL. Nutritional support for wound healing. Altern Med Rev 2003; 8:359-377. 
6. World Health Organization. International Classification of Functioning, Disability and Health. Geneva, Switzerland: WHO; 2001.

7. Casley-Smith J. Modern Treatment for Lymphoedema. Adelaide, Australia: The Lymphoedema Association of Australia, Inc.; 1994.

8. Casley-Smith JR, et al. There are many benzo-pyrones for lymphoedema. Lymphology 1997; 30:38-39.

9. Casley-Smith JR. Benzo-pyrones in the treatment of lymphoedema, Int Angiol 1999; 18:31-41.

10. Casley-Smith JR, Morgan RG, Piller NB. Treatment of lymphedema of the arms and legs with 5,6-benzo-[alpha]pyrone, N Engl J Med 1993; 329:1158-1163.

11. Blumberg S, Clough G, Michel C. Effects of hydroxyethyl rutosides upon the permeability of single capillaries in the frog mesentery, Br J Pharmacol 1989; 96:913-919.

12. Bruneton J. Pharmacognosie phytochimie des plantes medicinales [Pharmacognosy phytochemistry of medicinal plants]. Paris: Ed. Lavoisier; 1993.

13. Belcaro G, Rosaria Cesarone M, Ledda A, Cacchio M, Ruffini I, Ricci A, Ippolito E, Di Renzo A, Dugall M, Corsi M, Marino Santarelli AR, Grossi MG. O-(beta-hydroxyethyl)rutosides systemic and local treatment in chronic venous disease and microangiopathy: An independent prospective comparative study. Angiology 2008; 59(Suppl. 1):7S-13S.

14. Farinola N, Piller N. CYP2A6 polymorphisms: Is there a role for pharmacogenomics in preventing coumarininduced hepatotoxicity in lymphedema patients? Pharmacogenomics 2007; 8:151-158.

15. Zhou Y, Wang J, Yang W, Qi X, Lan L, Luo L, Yin Z. Bergapten prevents lipopolysaccharide-induced inflammation in RAW264.7 cells through suppressing JAK/STAT activation and ROS production and increases the survival rate of mice after LPS challenge. Int Immunopharmacol 2017; 48:159-168.

16. Hu W, Wang AM, Wu SY, Zhang B, Liu S, Gou YB, Wang JM. Debriding effect of bromela in on fire arm wounds in pigs. J Trauma 2011; 71:966-972.

17. Liu YT, Gong PH, Xiao FQ, Shao S, Zhao DQ, Yan MM, Yang XW. Chemical constituents and antioxidant, antiinflammatory and anti-tumor activities of Melilotus officinalis (Linn.) pall. Molecules 2018; 23:pii: E271.

18. Ricciuti S, Cardini C. Le Cumarine-Profilo farmacologico e terapeutico [Coumarins: pharmacological and therapeutic profile. Le cumarine]. 2005: 1-12. www.farmaciaeuropa .eu/wp-content/uploads/2011/03/Le-cuminarie.pdf (accessed August 7, 2020).
19. Scondotto G, Aloisi D. Cumarine naturali nel trattamento dell' edema linfatico [Natural cumarins in treatment of lymphatic oedema]. Linfologia Oggi 2002; 1:16-21.

20. Vettorello $\mathrm{G}$, et al. Contribution of a combination of alpha and beta benzopyrones, flavonoids and natural terpenes in the treatment of lymphedema of lower limbs at the $2 \mathrm{~d}$ stage of the surgical classification. Minerva Cardioangiol 1996; 44:447-455.

21. Foldi M, Foldi E, Kubik S. Foldi's Textbook of Lymphology. Munchen: Elsevier; 2004.

22. Morooka N, Futaki S, Sato-Nishiuchi R, et al. Polydom is an extracellular matrix protein involved in lymphatic vessel remodeling. Circ Res 2017; 120:1276-1288.

23. Michelini S, Campisi C, Ricci M, et al. Linee Guida Italiane sul Linfedema [Italian guidelines on lymphoedema]. Eur Med Phys 2007; 43(Suppl. 1-3):34-41.

24. Michelini S, Campisi C, Failla A, et al. Staging of lymphedema: Comparing different proposals. Eur J Lymphol 2006; 16:7-10.

25. Michelini S, Failla A. Linfedemi: Inquadramento diagnostico clinico e strumentale [Lymphoedema: clinical and instrumental diagnosis]. Minerva Cardioangiol 1997; 45(6 Suppl. I):11-15.

26. Campisi C, Michelini S, Boccardo F. Lymphology in medical and surgical practice. Italian guidelines looking towards Europe and World. Eur J Lymphol 2004; 14:26-28.

27. Albergati FG, Bacci PA. La Matrice extracellulare [The extracellular matrix]. Florence, Italy: Edizioni Officina Editoriale Oltrano; 2018.

28. Bonnans C, Chou J, Werb Z. Remodelling the extracellular matrix in development and disease. Nat Rev Mol Cell Biol 2010; 15:786-801.

29. Neumayer C, Fügl A, Nanobashvili J, Blumer R, Punz A, Gruber H, Polterauer P, Huk I. Combined enzymatic and antioxidative treatment reduces ischemia-reperfusion injury in rabbit skeletal muscle. J Surg Res 2006; 133:150-158.

Address correspondence to: Vincenzo Gasbarro, MD

Department of Vascular Surgery

Ferrara University

Polo Didattico di Cona clo Ospedale S. Anna, via Aldo Moro 8 Ferrara 44124 Italy

E-mail: s.michelini@acismom.it 